\title{
İbn Kuteybe’nin Şiir Anlayışı ve Şaire Bakışı
}

\author{
İSMAİL GÜLER \\ DOÇ. DR., ULUDAĞ ÜNIVERSITESİ İLAHIYAT FAKÜLTESİ
}

\begin{abstract}
ÖZET
İbn Kuteybe Arap şiir eleştirisini kuramsallaştırmaya çabalayan kişilerden sayılmaktadır. Onun şiir ve şairler hakkından yazmış oldukları bunu göstermektedir. Ancak onun bu alanda ne kadar başarılı olduğu hem yazdıklarının tutarlılığı hem de çağının diğer eleştirmenleri ve yazdıkları ile kıyaslandığında mümkündür. Bu makale onun şiir ve şairlerle ilgili ünlü eserinin mukaddimesinde ileri sürdüğü görüşleri ele almaya ve şiir eleştirisinin neresinde durduğunu tespit etmeye yönelik kaleme alınmıştır.
\end{abstract}

\section{SUMMARY}

IBN QUTAYBA'S UNDERSTANDING OF THE POEM AND HIS VIEW TO THE POET

What he has written shows that Ibn Qutayba is one of the writers who tried to put the theory of Arabic poetry. But how successful he is in this area We can judge his work with its internal consistency and with comparison his critics with ones of his time. This article was written to detect Ibn Qutayba's place in the poetry criticism area considering his opinions about poets and poetry in his introduction to his famous book "al-Shi' $r$ wa al-Shu'arâ".

İbn Kuteybe (ö.276/889) Abbasîlerin güçlü olduğu zamanlarda yaşamış ve çeşitli ilimlerde ürünler verdiği gibi şiir ve şairlerle ilgili eserler de yazmış ve eleştiriye dair kanaatlerini bu eserlerinde dile getirmiştir. Ancak diğer kitaplarında eleştiri ile ilgili kanaatleri az ve dağınık iken şiir ve şairlerin biyografilerine dair müstakil bir kitap (eş-Şi'r ve `ş-Şu'arâ $)^{1}$ yazmış eleştiri ile ilgili kanaatlerini yoğun olarak bu eserinde ele almıştır. ${ }^{2}$ Kitabın giriş kısmında şiir ve şair hak-

1 İbn Kuteybe ve eserinin değişik baskı ve çevirileri hakkında geniş bilgi için bkz. Yıldız, Musa; "eş-Şi'r ve 'ş-Şu'arâ" Maddesi, DİA, c. 39 s. 180

2 Abdulâl, Abdusselâm Abdulhafîz; Nakdu 'ş-Şi'r beyne İbn Kuteybe ve İbn Tabataba el-'Alevî, s. 106 
kındaki kanaatlerini örneklerle açıklamış, ayrıca ilerleyen sayfalarında değişik şair biyografilerinden bahsederken birtakım değerlendirmelerde bulunmuştur. $\mathrm{Bu}$ çalışmada biz bu eseri temel alarak özellikle giriş kısmındaki bilgilerden hareketle onun şiir ve şair hakkındaki görüşlerini değerlendireceğiz.

\section{A. GÜZEL ve KÖTÜ ŞİIR}

İbn Kuteybe eleştirel görüşlerini aktarırken eskileri taklit etmediğini, başkasının estetik yargılarını tekrarlamadığını ve bu konuda orijinal olmaya çabaladığını belirtir. ${ }^{3} \mathrm{O}$, güzelliği ve çirkinliği açısından şiire bakar ve yargılarını şu dört kategoride ele alır:

1. Lafzı ve anlamı güzel,

2. Lafzı güzel ve hoş, anlamı yüzeysel,

3. Anlamı iyi fakat lafzı aynı güzellikte değil,

4. Hem lafzı, hem de anlamı yetersiz.

O, ulemanın çoğunun şiirlerini dördüncü türden sayar. Asma'î (ö. 216/831), İbnu'l-Mukaffa' (ö. 142/759), Halîl b. Ahmed (ö.175/791) gibi âlimlerin nazmettikleri bu türdendir. Fakat Halef el-Ahmer'in (ö. 180/796) şiirini ulema grubundan ayrı tutar. Onun hem şiirinin bol, hem de şairlik yeteneğinin iyi olduğunu belirtir.

İbn Kuteybe ulema şiiri ile şuarâ şiirinin farklı olduğunu söylerken haklıdır. Zira âlimin şiirinde anlama ve sebep arama baskın özellik iken, şairde hissetme ağır basar. Şiir aklın değil vicdanın dili olmalıdır. Gerçek şair hissettiğini, vicdanında duyduğunu güzelce dile getirebilendir. ${ }^{4}$

Görüldüğ̈ gibi İbn Kuteybe güzellik ölçüsünü lafız-mana ekseninde döndürmekte, bu ikiliyi de; güzel veya çirkin hükümleri ile yargılamaktadır. ${ }^{5}$ İbn Kuteybe bu tasnifinde içinde yetiştiği kültürün bir parçası olan Aristo mantığından etkilenmiştir. Ayrıca tasnifin lafız-mana ekseninde dönmesi yine çağının hararetli tartışma konularından olan Kur'an'ın icazının lafzında mı yoksa manasında mı olduğunun edebiyat alanına sıçramasının sonucudur. ${ }^{6}$

3 eş-Şi'r ve`ş-Şu'arâ, I/62

4 Muvâfî, Osmân; Dirâsât fi' 'n-Nakdi' l-'Arabî, s. 94

5 Hasen, Huseyn el-Hâc; en-Nakdu 'l-Edebî fi Âsâri A'lâmih, s. 196

6 Muvâfî, age, s. 94-95 
Muhammed Mendûr, İbn Kuteybe'nin anlayışını eleştirirken ${ }^{7}$ onun yarg1larında "hoş", "tatlı", "eksik” ve "yetersiz" gibi öznellik ifade eden hükümler vermesi dolayısıyla zevkçi bir eğilim taşımakla birlikte bu yargılarının temelinde de öncekilerden devraldığı şu iki esasın bulunduğunu belirtir;

a-) Lafız anlamın hizmetindedir. Bir anlam değişik lafızlarla dile getirilebilir ve bunların da bazısı güzel, bazısı da yetersizdir.

b-) Her beytin bir anlamı olmalıdır.

Mendûr'a göre İbn Kuteybe her beyitte bir anlam ararken yine bir ön kabulden hareket etmektedir ki o da bir şeyin anlamlı olması demek düşünsel veya ahlakî bir içerik barındırması demektir. Örneğin Curcânî (ö.471/1078) ${ }^{8}$ ve İbn Cinnî’nin (ö.392/1002) ${ }^{9}$ güzel buldukları ancak onun lafzı güzel ama içeriği boş dediği 'Ukbe b. el-Mudarrib'e nispet edilen aşağıdaki beyitleri değerlendirirken beyitleri şiir formundan çıkarıp düz yazıya aktardıktan sonra içinde bir fikir bulamadığı için beğenmemektedir.
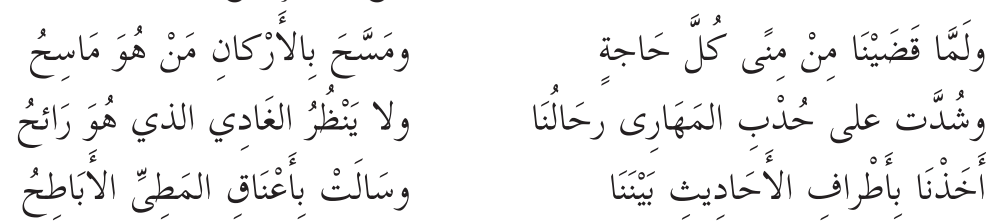

(Mina'daki bütün görevlerimizi yerine getirip, herkes rükünlere selam verdikten sonra yorgun ve bitkin develere yüklerimiz sarıldı. Gelenin gidenle ilgilenecek hali yoktu. Aramızda muhabbetle yola koyulduk ve vadiler binek hayvanlarıyla kaynıyordu.)

Yine onun güzel dediği Ebu Zueyb'e ait şu beyit de güzelliğini ahlakî bir içerik taşımasından almaktadır:

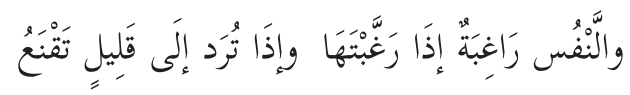

(Nefis sen onu şımarttıkça ister, eğer aza mecbur bırakılırsa kanaat getirir.)

\section{B. ESKİ - YENİ TARTIŞMASI}

Eski-yeni tartışması birinci hicri asrın sonları ile ikinci asrın başlarında şiirin eski sanatsal ilkelerine bağlı kalmak isteyen bir eğilim ve karşısında bu

7 Mendûr, Muhammed; en-Nakdu'1-Menhecî 'inde '1-'Arab, s. 32 vd.

8 el-Curcânî, Abdulkâhir; Esrâru'l-Belâğa, s. 21

9 İbn Cinnî, el-Hasâis, I/218 
ilkelerden kurtulup içerik ve biçimde yenilik arayan bir başka eğilimin ortaya çıkmasıyla baş göstermiştir. Birinci nesilden dilci ve raviler; Ebu 'Amr b. el'Alâ (ö. 154/771), Halef el-Ahmar, Hammâd er-Râviye (ö.160/776) Câhiliye dönemi şiirine hususi bir bağl1lık gösteriyorlar, rivayetlerinde bu şiirleri esas alıyorlar ve yeni (muhdes) şiire ilgi duymuyorlardı. Eskiye taassup ikinci nesil dilci ve raviler tarafından da devam ettirildi. Asma' î, Ebû 'Ubeyde (ö.209/824) ve İbnu'l-A'râbî (ö.231/846) bunlardandır. Ancak bunların eski anlayışı biraz değişmiş ve sınırları genişlemişti. Zira bunlara göre eski, sadece Câhiliye şiirleriyle sınırlı olmayıp hicretin yüz ellinci yılına kadar olan ve istişhad sınırını belirleyen tarihi de içine almaktaydı. Öyleyse zaman unsurunun bu eleştirmenlerin şiir eleştirisi üzerinde ektisinin büyük olduğu söylenebilir. Öyle ki bunlar arasında şiirin tarihi ne kadar eskiyse yeni şiire nazaran o kadar daha makbuldür gibi bir söz de dolaşmaktayd $1 .{ }^{10}$

Eski-yeni tartışmasının sıcaklığını zamanına kadar koruduğu İbn Kuteybe'ye gelince o, seçimlerinde ve yargılarında adaletli davrandığını, eskiyi sadece önceliği dolayısıyla kutsayıp, sonra geleni de gecikmişliğinden dolayı küçük görmediğini söyler ve eskilerle yeniler karşısında tarafsız davrandığını, haklarını teslim ettiğini belirtir. Çağında herkesin böyle yapmadığını hatta tersinin bile söz konusu olduğunu, değersiz bir şiiri şairinin öncekilerden olması dolayısıyla beğenen, çok sağlam bir şiiri de söyleyeni sadece çağdaşı olduğu için beğenmeyen eleştirmelerin varlığından bahseder. ${ }^{11}$ Allah şiir ve belagati belli bir çağa yahut belli bir topluluğa özgü kılmamıştır. Her eski şair çağının yenisi değil midir? Cerîr, el-Ferezdak, el-Ahtal zamanlarında yeni (muhdes) şairler idiler. Ebu 'Amr b. el-'Alâ' dan “şu yeni şiir o kadar bol ve güzel ki, onu da rivayet edesim geliyor" dediği aktarılmıştır. ${ }^{12}$

İbn Kuteybe eskiyi bütünüyle iyi ve yeniyi de bütünüyle kötü görmemekle beraber şiirin güzel olabilmesi için eskilerin mazmun sistemine uymasını gerekli görmektedir. Ona göre şair, eserinde eskilerin yolundan ayrılıp mâmur ve sağlam yapılı menzillerin önünde durarak şiire başlamamalı, yolculuğunu deveden başka bir binek hayvanı ile yapmamalıdır. Hatta memdûhuna giderken geçtiği yol, nergis (narcîs), mersin (âs) ve gül (vard) biten bir arâzi olamaz.

10 Muvâfî, age, s. 86

11 eş-Şi'r ve'ş-Şu'arâ, I/62

12 Age, I/63 
Çünkü eskiler kasîdelerinde, yavşan otu (şîh), fesleğen (hanva) ve bir nevi papatya (arâra) yetişen bâdiyelerden geçmişlerdir. ${ }^{13}$

Görüldüğ̈̈ gibi eskiye gözü kapalı bağlı kalmayan, yeniyi de tamamen reddetmeyen İbn Kuteybe yeninin kabulünü güzellik şartlarına uymak yanında eskinin ölçüsüne sadık kalmaya da bağlamaktadır. Yani eskinin iyi ve güzel ölçütü yeni için de beğeni ve kabul ölçütünü oluşturmaktadır. ${ }^{14}$

Fakat eleştirmenimizin ve diğerlerinin sert hükümlerine ve yadırgamalarına rağmen hem o dönemdeki hem de daha sonra gelen şairler şiirlerinde "nergis"ten ve "gül"den bahsetmişlerdir. Ebû Nuvâs (ö.198/813), Ebu'l-'Atâhiye (ö.210/825) ve el-Mütenebbî (ö.354/965) gibi şairler kasidenin içyapısını arzu ve mizaçlarına göre değiştirerek kendilerini kabul ettirebilmişlerdir. ${ }^{15}$

\section{DOĞALLIK ve ZORLAMA}

İbn Kuteybe'nin çağında yaygın olarak kullanılan ve terimleri tam oturmamış olan bir başka ölçüt de şiirde veya şairde doğallık ve suni' iliktir. ${ }^{16}$ Bir kısım eleştirmene göre şairin zorlanmadan güzel söylemesi hem şiirinin hem de şairin şair yarad1lışlı (matbu), aksinin ise zorlama ve doğal olmayan (masnu - mütekellif) olmasına hükmedilir. Ancak İbn Kuteybe'ye göre hem matbu hem de mütekellif şiir güzel olabilir. O matbu olmakla yaradılıştan geleni, mütekellif olmakla da üzerinde çalışılmış güzel şiiri kastetmektedir. Mütekellif şair şiirini cendereye sokarak doğrultur, uzun süre onu ayıklar, defalarca gözden geçirir. Zuheyr (ö.609 m.) ve el-Hutay`e (ö.59/678) bu gibilerdendir. Eleştirmenimiz bu ikisinin benzerlerinin el-Asma'î'nin tabiriyle "şiirin köleleri” olduğunu, zira matbu şairler gibi davranmayıp şiirlerini ayıklamaya tabi tuttuklarını aktarır, hatta şairlerin kendi ağızlarından yaptıkları bu işin güzel şiir için gerekli olduğuna dair ifadeler duyulduğunu belirtir. Bazı şairler de şiirlerini oluştururken nasıl seçici ve titiz davrandıklarını bizzat yine şiirle söylemişlerdir. ${ }^{17}$

Mendûr, İbn Kuteybe'nin bu anlayışını da eleştirerek onun tab' ve tekellüf konularında doğru teşhislerde bulunmadığı kanaatini dile getirir. Zira

13 Çetin, Nihad; Eski Arap Şiiri, s. 73; eş-Şi'r ve 'ş-Şu'arâ, I/76-77

14 Muvâfî, age, s. 89

15 Çetin, age, s. 74

16 Hasen, age, s. 197

17 eş-Şi'r ve'ş-Şu'arâ, I/78 
Mendûr'a göre şiir her şeyden önce bütünlük isteyen bir sanatsal çabadır. Şairin doğasından birden bire fışkırır, şair onu daha sonra rötuşlayıp daha da güzelleştirebilir. Ortada biri matbu, yani şiirinde hiçbir düzenlemeye gerek duymadan onu son haliyle ortaya koyan ve bir de zaman içinde parça parça düşünüp söyleyen ve son noktayı en sonunda koyan (mütekellif) iki ayrı şair grubu yoktur. Bu aşamalar içi içedir. ${ }^{18}$ Yani şiir, şairin doğası (tab'), sebep (dafi'), irade, zenaat (sınâ'a) ve çaba (cuhd) sonucunda ortaya çıkar. ${ }^{19}$

Şairlik doğasının ürünü olan bir şiiri şairin daha sonra güzelleştirmesi İbn Kuteybe'nin ileri sürdüğü gibi tekellüf değildir. Asıl tekellüf şairin bir düşünceyi önce zihninde oluşturup sonra buna şiirsel bir kalıp aramasıdır. Asıl zorlama ve yapmacıklık budur. Bu tekellüfün örneğini Ebu Temmâm'da bolca görürüz. Fakat Zuheyr ve el-Hutay'e'nin şiirlerini rötuşlamaları bu anlamda tekellüf değildir. ${ }^{20}$

Bu noktada Mendûr'a göre İbn Kuteybe ortaya koyduğu örneklerden anlaşıldığı kadarıyla;

a- Tekellüf (zorlama) ile Zuheyr ve el-Hutay'e'nin yapmış olduğu gibi şiiri uzun bir zaman diliminde gözden geçirme, ayıklama ve düzeltmeyi,

b- Doğallık ile doğaçlamayı (irtical) birbirine karıştırmıştır. Öyle ki doğal (matbu) şiirin doğaçlama (murtecel) ile aynı olduğunu söylemiştir. ${ }^{21}$

İbn Kuteybe'nin tekellüfü Zuheyr ve el-Hutay'e'nin yaptı̆̆ gibi şiiri bekletmek ve onu ayıklamaya tabi tutarak daha da güzelleştirmek anlamına aldığı gibi olumsuz ve zorlama anlamına aldığına dair görüşleri vardır. Örneğin o bu olumsuz anlamı ile mütekellif şiirdeki zorlamanın ilim sahibine gizli kalmayacağını, şiirin uzun bekleme ve zorlanma sonunda ter dökülerek söylenmiş olduğunun içindeki hataların çokluğundan, gerektiği halde söylenmemiş veya gerek olmadığı halde söylenmiş şeylerden anlaşılabileceğini ileri sürer. ${ }^{22}$

\section{D. ŞIïRIN KISIMLARI ARASINDAKI ORANTI ve ŞIïRIN BÜTÜNLÜĞÜ}

Eleştirmenimiz iyi bir şiirin özellikle medhiye türünden bir şiirin nasıl olması gerektiğini ve ölçülerini ilk ortaya koyan kişilerdendir. ${ }^{23}$ Buna göre şiir

18 Mendûr, age, s. 40

19 Age, s. 39

20 Age, s. $40-41$

21 Age, s. 39

22 eş-Şi'r ve 'ş-Şu' arâ, I/88

23 Mûsâ, Halîl; Vahdetu'l-Beyt fi'n-Nakdi'l-'Arabîyyi'l-Kadîm, et-Turâsu'l-'Arabî dergisi, çevri- 
söyleyen kişi önce sevgilinin yurdunu, kalıntı ve izlerini zikreder, ağlar, sızlanır, sevgilinin konakladığı yere seslenir, göçüp giden sevgilinin hatırlanmasına vesile olsun diye arkadaşlarını durdurur. Sonra şair nesib kısmına başlar; hasret ve ayrılık acısının şiddetinden, aşk ve arzusunun dayanılmazlığından şikâyet eder ki kalpleri kendine meylettirsin, ilgi ve alakayı çekebilsin. Zira nesîb kısmında sevgilinin güzelliklerini sayıp dökmek ve onları övmek insanların hoşuna gider, kalplerde daha sağlam bir yer edinir. Allah, kadın sevgisini ve ona kur yapma duygusunu insanın içine yerleştirmiştir. İster helal ister haram olsun kadına ilgi duymayan ve bu konuda bir payı olmayan insan yok gibidir. Şair ilgiyi konuya çektiğinden emin olduktan sonra, sevgilinin aralarındaki hukuka riayet etmesini ister, sıkıntılı ve uykusuz geçen zamanlardan, gece yolculuğu ve gündüzün yakıcılığı ile bineğinin yorgunluğundan şikâyet eder. Bundan sonra övgüye başlar. ${ }^{24}$

İbn Kuteybe'ye göre usta şair bu usule uyan, şiirin kısımları arasında dengeyi kurandır. İyi bir şair kısımlardan birini diğerinden üstün tutmaz, dinleyiciyi bıktıracak kadar sözü uzatmayacağı gibi, devamını bekleyen karşısında da kısa kesmez. Konu ile ilgili olarak Emevîlerin Horasan valisi Nasr b. Seyyâr'ın meclisinde geçen bir olayı örnek verir. Anlatımına göre bir şair valinin huzuruna gelerek onu yüz beyitli bir şiirle övmek ister. Ancak övgü kısmı on beyitte kalınca Vali: Vallahi hakkımda söylemen gereken bütün tatlı sözleri ve hoş anlamları teşbîb (nesîb) kısmında harcadın. Eğer beni övmek diliyorsan nesîb kısmında orta yolu tut. Bir sonraki sefer de şair tek bir beyitle kendisini övünce Vali: en öyle, ne de böyle, ikisi arasında bir yol tut, dedi. ${ }^{25}$

Eleştirmenimizin yukarıda ileri sürdüğü bütünlük kuralları medîh türü şiir için geçerli iken, mersiyede bu kurallar söz konusu olmamıştır. Zira mersiye şairleri ağıttan başka bir konuya geçmemişlerdir. Bu yüzden ve ayrıca daha çok mersiye söylediklerinden İbn Sellam eserinde mersiye şairlerini ayrı tutmuş onları diğer tabakalara katmamıştır. Ayrıca medîh şairi de olsa bütün şairler tam olarak yukarıda verilen bütünlük ölçüsüne uymamış olup, geneli açısından bakıldığında uygulandığı gözlemlenebilen bir ölçüt olmuştur. ${ }^{26}$

miçi: http://www.awu-dam.org/trath/35-36/turath35-36-006.htm

24 eş-Şi'r ve'ş-Şu'arâ, I/75

25 Age, I/76

26 Muvâfî, age, s. 91 
İbn Kuteybe'nin şiirde bütünlük arayışına dair attığ i ilk önemli adımlardan sayılan $^{27}$ ve zorlama (tekellüf) konusunu ele alırken mütekellif şiir türüne verdiği örnek parçaları (beyitleri) arasında uyum olmayan şiirdir. Konuyla ilgili olarak şair Ömer b. Lece'in bir başkasına söylediği sözü hatırlatır. Ömer o şaire; "ben senden daha iyi bir şairim zira ben bir beyit söylediğimde ardından kardeşini söylerim, sen ise amca çocuğunu söylersin" ${ }^{28}$ demektedir.

Bütünlük arayışına bir örnek de eleştirmenimizin aktardığ 1 Abdullah b. Salim'e ait bir sözdür. Abdullah, şair Ru'be'ye oğlunu şiir söylerken dinlediğini ve hoşuna gittiğini söyleyince, Ru'be "doğru, ama onun şiirinde 'kırân' parçalar arası uyum yoktur.” diye cevap vermiştir. ${ }^{29} \mathrm{Bu}$ atıflar şiirde bütünlük arayışının bulunduğunu göstermeye yeterli olmakla birlikte konu ile ilgili derli toplu bir kurama ulaşılabildiğini söylemek güçtür.

\section{E. ŞIIIR SÖYLEMEYE UYGUN ZAMANLAR}

İbn Kuteybe'ye göre şiirin güzel olmasını sağlayan birtakım durumlar da söz konusudur. Bunlar şairin beklenti (شمع) veya arzu (شوق) halinde olmas1, içki (شراب)meclisinde, ya da coşku (طرب)ve kızgınlık (غضب) halinde olmasıdır. ${ }^{30} \mathrm{O}$, bu gibi durumlarda şiir söylendiğinde daha güzel olduğuna dair şairlerin ağzından birkaç örnek de vermektedir. ${ }^{31}$ Yine o yukarıda söylenen ve şairin psikolojik durumları diyebileceğimiz şiir söylemeye uygun durumlara ek olarak uygun vakitlerden de bahsetmiştir. Örneğin uyku bastırmadan önceki gecenin ve kahvaltı etmeden önceki gündüzün ilk saatleri, ilaç içilen gün, yalnızlık, hapis ve yolculuk vakitleri gibi uygun zamanlardan bahsetmektedir. ${ }^{32}$

Bellidir ki bunlar bütün şairler için geçerli şartlar olamaz fakat o bunları, aktardığı rivayetlere ve bazı şahsî gözlemlerine dayanarak ileri sürmüş gözükmektedir. Yoksa bir şair için iyi şiir belli esrime anlarına gerek duyarken diğer biri için bilincin tam yerinde olması daha uygun olabilir. Neşeli halde iken mersiye söylenemeyeceği gibi bazı vakitler sadece belli şiir türleri için uygun olabilir.

27 Hasen, age, 198

28 eş-Şi'r ve 'ş-Şu'arâ, I/90

29 A.y.

30 Age, I/78

31 Age, I/80

32 Age, I/81 


\section{F. ŞIIİII DEĞERLENDİRMEDE GEÇMIŞìN BİLGİSINNE DUYU- LAN İHTIYAÇ}

İbn Kuteybe'ye göre nasıl ki din bilimlerinde geçmişten aktarılan bilgiye kaçınılmaz bir gereksinim varsa aynı durum şiir için de geçerlidir. Zira şiirde yabancı (ğarîb) lafizlar, farklı lehçelere ait kelimeler, nadir kullanılan (vahşî) kelimeler bulunmakta, değişik ağaç, bitki, yer ve su isimleri geçmektedir ki bütün bunlar zekâ ile değil ancak duyum ile bilenebilecek şeylerdir. ${ }^{33}$ Eleştirmenimiz şiir aktaranların bu noktalardaki eksiklikleri yüzünden şiirin bazı kelimeleri bozularak aktarıldığını belirtir ve buna dair birkaç örnek verir.

\section{G. ŞIIIR TEKNİĞi AÇISINDAN ELEŞTÍRILER}

Genel şiir ve şair eleştirilerinden sonra İbn Kuteybe eskiden beri aktarıla gelen bazı teknik hatalar üzerinde durur. Bunlar; kafiyelerde irab farkl11ı̆̆ (ikva / ikfa), rediflerin farklılığı (sinâd), kafiyenin iki defa tekrarı (îtâ) gibi şiir kusurları ve şiirlerde yapılan tashif hatalarıdır. ${ }^{34}$ Eleştirmenimiz bu konularda yeni bir şey söylememekte eskileri tekrarlamaktadır. ${ }^{35}$

\section{SONUÇ}

İbn Kuteybe, mantığı zevkinden, düşüncesi pratiğinden daha iyi biridir. Şiiri değerlendirmede kişisel kanaatin esas olmasını istemekle isabet etmiş, matbu şiirin sonunun başından belli olan şiir olduğunu söyleyerek doğru karar vermiştir. Mütekellif şiiri de bu bütünlükten yoksun olmak biçiminde tanımlamıştır. Fakat şiiri lafız ve anlamlarının güzelliğine göre bölümlerken yargılarıyla zevklerini birbirine karışmıştır. Matbu ve mütekellif şiiri ayırırken tabii olan ile irticalî (doğaçlama) olanı, zaman içinde ayıklanmış (teskîfî) olanla zorlama (tekellüfî) olanı karıştırmıştır. Bütün bunlarla birlikte o Arap şiirinin Yunan mantığ 1 içinde boğulmasına, eskinin sadece eskiliği yüzünden kabul, yeninin de sadece yeni olması dolayısıyla reddedilmesine karşı durmuştur. Bütün bunlardan sonra denilebilir ki; İbn Kuteybe, Amidî gibi şiir eleştirisini bir yönteme oturtabilmiş bir eleştirmen değildir. ${ }^{36}$ 
Mendûr'un da belirttiği gibi İbn Kuteybe şiiri felsefe ve mantığın etkisinden kurtarmaya çabalamış ise de bilim adamlığı yönü, eleştirmen ve edebî zevk yönüne baskın çıkmış gözükmektedir. Zira hem edebî üretim hem de onun eleştirisi her şeyden önce zevk ve his yönünün ağır basmasını geretirmektedir. Ancak o şiir eleştirisinde bir kuram oluşturma yönünde atılmış ilk önemli adımların sahiplerinden biri olması açısından önemlidir.

\section{KAYNAKLAR}

Abdulâl, Abdusselâm Abdulhafîz; Nakdu'ş-Şi`r beyne İbn Kuteybe ve İbn Tabatabâ el-`Alevî, Kahire 1978

el-Curcânî, Abdulkâhir; Esrâru'l-Belâğa, H. Ritter neşri, Kahire 1979

Çetin, Nihad; Eski Arap Şiiri, İstanbul 1973

el-Hârisî, Muhammed; İbn Kuteybe ve Nakdu'ş-Şi rr, Mekke 1976 (Basılmamış Yüksek Lisans Tezi)

Hasen, Huseyn el-Hâc; en-Nakdu'1-Edebî fi Âsâri A'lâmih, Beyrut 1996

İbn Cinnî, el-Hasâis, M. A. Neccâr neşri, Kahire 1987

İbn Kuteybe, eş-Şi'r ve'ş-Şu' arâ, A. M. Şâkir neşri, Kahire 1982

Mendûr, Muhammed; en-Nakdu'1-Menhecî inde'l-Arab, Kahire 1996

Mûsâ, Halîl; Vahdetu'1-Beyt fi'n-Nakdi'1-'Arabîyyi'1-Kadîm, et-Turâsu'1Arabî dergisi, çevrimiçi: http://www.awu-dam.org/trath/35-36/turath3536-006.htm

Muvâfî, Osman; Dirâsât fi'n-Nakdi'1-'Arabî, Kahire 2000

Yıldız, Musa; "eş-Şi'r ve'ş-Şu'arâ" Maddesi, DİA, c. 39 s. 180 